\title{
Factors associated with the initiation of testosterone replacement therapy in men from the 45 and Up Study
}

Yan Cheng, Deborah Bateson, Kristine Concepcion, Mary Stewart, Michael Lowy, Sally Sweeney, Jane Estoesta, Kevin McGeechan

\section{Background and objectives \\ There have been large increases in testosterone prescribing since 2000 . The aim of this study was to identify factors associated with testosterone replacement therapy (TRT) initiation in men.}

\section{Methods \\ Data were from the 45 and Up Study, an ongoing cohort study involving 266,942 participants from New South Wales aged $\geq 45$ years. Baseline data (2006-09) were linked to administrative data on government-subsidised prescriptions and medical services.}

\section{Results}

The study included 105,429 men. In two years following baseline, 2.9 per 1000 men (95\% confidence interval: $2.6,3.2$ ) had initiated TRT. Men with self-rated poor health, those treated for osteoporosis; anxiety, depression or high blood cholesterol, and those who lived in major cities or were aged 55-74 years had greater odds of TRT initiation. In the six months before TRT initiation, $41 \%$ of men had a hormone test record.

\section{Discussion}

The high rate of TRT initiation and low rate of recommended investigations suggest TRT may have been prescribed outside recommended indications.
TESTOSTERONE REPLACEMENT THERAPY (TRT) is clinically indicated for men with proven hypogonadism. ${ }^{1,2}$ However, the therapeutic benefit to men who are not clinically deficient remains unclear. A systematic review found no TRT benefit for various outcomes. ${ }^{3}$ Conversely, TRT trials sponsored by the National Institutes of Health showed benefits; however, they also showed potential harms..$^{4-6}$ Despite lack of evidence for wider use, there have been large increases in testosterone prescribing in Australia ${ }^{7}$ and globally ${ }^{8-10}$ since 2000.

The increasing testosterone demand has raised concerns of unwarranted offlabel use. ${ }^{9}$ The 2000 Endocrine Society of Australia (ESA) guidelines, updated in 2016, recommended that TRT should be started after two separate hormone assays measuring luteinising hormone (LH), follicle-stimulating hormone ( $\mathrm{FSH}$ ) and testosterone. ${ }^{1,2}$ Where the diagnosis is not clear, referral to an endocrinologist is recommended..$^{2}$ In April 2015, the Pharmaceutical Benefits Scheme (PBS) TRT criteria were updated to require lower testosterone levels $(6 \mathrm{nmol} / \mathrm{L}$ rather than $8 \mathrm{nmol} / \mathrm{L})^{11}$ prior to TRT initiation. Additionally, the PBS subsidises TRT for symptomatic men without evidence of pituitary or testicular disease only if the general practitioner (GP) provides evidence of androgen deficiency confirmed by two separate blood tests and a specialist (endocrinologist, urologist or Member of the Australian Chapter of Sexual Health Medicine) referral.

Understanding the TRT prescription context strengthens prescribing practice. However, few studies have examined this, and none in
Australia. We aimed to investigate the sociodemographic and clinical factors associated with TRT initiation among middle-aged and older men, and assess whether hormone tests or specialist visits occurred before initiation.

\section{Methods}

\section{Sampling and procedures}

Data were obtained from the Sax Institute's 45 and Up Study, an ongoing cohort study in New South Wales (NSW), Australia. Prospective participants were randomly sampled from the Department of Human Services (formerly Medicare Australia) enrolment database, which provides near-complete coverage of the population. People aged $\geq 80$ years and residents of rural and remote areas were oversampled. A total of 266,942 participants completed the baseline questionnaire (between January 2006 and December 2009) and gave signed consent for follow-up and linkage of their information to routine health databases including the Medicare Benefits Schedule (MBS) and PBS database. Of those invited, $18 \%$ participated and $11 \%$ of the NSW population aged $\geq 45$ years participated. ${ }^{12}$ The study is described elsewhere ${ }^{12}$ and questionnaires are available at www. saxinstitute.org.au/our-work/45-upstudy. The 45 and Up Study was approved by the Department of Health and Aging Departmental Ethics Committee (Approval number 1/2005) and the University of New South Wales Human Research Ethics Committee (Approval number HC15408).

PBS and MBS records from 2004-14 were included in the current analysis. 
These datasets were supplied by the Department of Human Services, and the Sax Institute ${ }^{12}$ linked them to the baseline 45 and Up Study data.

\section{Outcomes}

TRT initiation was defined by a PBS prescription filled for a testosteronebased drug (Anatomical Therapeutic Chemical code G03BA03) up to 24 months after the baseline survey for males with no prescription filled 24 months prior. Baseline surveys were completed between 2006 and 2009; therefore, the end of two-year follow-up was between 2008 and 2011. It is noted that the PBS records do not account for all testosterone prescribing, such as private scripts. Participants who self-reported holding a Department of Veterans' Affairs (DVA) card were excluded as they have access to a broader range of subsided medications under a separate government program.

We identified whether men had a hormone test (MBS item number 66695) in the six months before TRT initiation. This MBS item includes hormone assays for testosterone deficiency, but it also includes insulin assays; therefore, we excluded participants with diabetes on the basis of survey or prescription data. This may have the effect of underestimating the amount of TRT initiation in the population. A specialist visit was defined as any claim under MBS Category 1 attendances, which comprise a wide range of specialist consultations including but not specifying an endocrinologist, urologist or a Member of the Australian Chapter of Sexual Health Medicine consultation.

\section{Explanatory variables}

We examined whether various demographic and clinical characteristics were associated with TRT initiation. The demographics were age, education, area of residence, marital status, country of birth, language spoken at home and work status.

The clinical characteristics included body mass index (BMI), smoking, alcohol intake, physical activity, ${ }^{13}$ physical impairment, ${ }^{14}$ fruit and vegetable intake, self-rated health, need for help because of long-term illness or disability, history of enlarged prostate/prostate cancer/ prostatectomy, prostate symptom score, vasectomy, fracture in the past five years and psychological distress. ${ }^{15}$ We created dichotomous variables for history of heart disease, high blood pressure, high cholesterol, stroke and anxiety/depression on the basis of self-reported (at baseline) doctor-diagnosis of, or recent treatment in the last month for, these conditions, and dichotomous variables for inability to maintain an erection, treatment for osteoporosis and low bone density. Full details of the categorisation of variables is available in the online Appendix.

\section{Statistical analysis}

Frequency counts and percentages were calculated for participant characteristics. We calculated the percentage of participants who had TRT initiated and had a hormone test or specialist visit before TRT initiation. We tested the difference in characteristics between the TRT group and non-TRT group with chisquare tests. We used logistic regression to explore the factors associated with the initiation of TRT. All factors were included in this multivariable model, and we report adjusted odds ratios (aOR) and $95 \%$ confidence intervals (CI) for significant $(P<0.05)$ factors. Multiple imputation was performed using the fully conditional method to account for missing data. Twenty imputation models were created, and the parameter estimates were combined using Rubin's rules. ${ }^{16}$ Data were analysed using SAS version 9.4 (SAS Institute Inc.).

\section{Results}

\section{Respondents' demographics and clinical characteristics}

There were 123,846 male baseline participants in the 45 and Up Study, of which 105,429 were analysed. The mean age was 62.9 years. The following participants were excluded:

- 4,312 with a DVA white or gold care card

- 13,465 with a doctor-diagnosis of, or recent treatment for, diabetes

- 640 with testosterone PBS prescriptions filled 24 months before baseline.
Factors associated with TRT initiation

In the two-year follow-up period, 2.9 per 1000 men (302) had a prescription filled for TRT (95\% CI: 2.6, 3.2). Univariate analyses showed that the demographics associated with TRT initiation were age, area of residence and work status (Table 1), while associated clinical characteristics were BMI, physical activity level, physical impairment, self-rated health, long-term illness or disability, prostate symptom score, erection difficulty, vasectomy, osteoporosis or low bone density, fractures in last five years, psychological distress, history of heart disease/heart attack/angina, high blood pressure, high blood cholesterol and anxiety/depression (Table 2).

In the multivariable model, men aged 55-74 years, residing in major cities, with a history of osteoporosis, recent fractures, high cholesterol, anxiety/depression or lower self-rated health had greater odds of TRT initiation (Table 3).

Among the men who initiated TRT, 255 (84\%) had TRT prescribed again in the first year after the initial prescription. The numbers decreased to 163 (53.9\%), 143 (47.4\%) and 143 (47.4\%) in the second, third and fourth years, respectively. There were 117 (38.7\%) who had a TRT prescription filled in each of the four years following initiation.

\section{Hormone tests and specialist visits before TRT initiation}

Among 302 respondents who initiated TRT, 125 (41\%) had a hormone test and $178(59 \%)$ had a specialist visit in the six months before the prescription was dispensed.

\section{Discussion}

During the two-year study period, three per 1000 men initiated TRT and nearly $40 \%$ of them continued the testosterone use in the following four years. Factors associated with TRT initiation were older age and residing in a major city. Almost $60 \%$ of men who initiated TRT did not have a prior hormone test, which suggests that prescribing of TRT was inconsistent with contemporaneous clinical guidelines. 
Table 1. Demographics of participants who had testosterone replacement therapy (TRT) initiation or not in the two-year follow-up (n/\%)

\begin{tabular}{lccccc}
\hline $\begin{array}{l}\text { Demographics } \\
\text { characteristics }\end{array}$ & $\begin{array}{c}\text { TRT } \\
\text { initiation } \\
(\mathrm{n}=302)\end{array}$ & $\begin{array}{c}\text { TRT non- } \\
\text { initiation } \\
(\mathrm{n}=105,127)\end{array}$ & $\begin{array}{c}\text { Total } \\
(\mathrm{n}=105,429)\end{array}$ & $P^{*}$ \\
\hline Age group & $60(0.2)$ & $29,278(99.8)$ & $29,338(27.8)$ & 0.0006 \\
\hline $45-54$ years & $126(0.4)$ & $33,993(99.6)$ & $34,119(32.4)$ & \\
\hline $55-64$ years & $75(0.3)$ & $24,332(99.7)$ & $24,407(23.2)$ & \\
\hline $65-74$ years & $41(0.2)$ & $17,524(99.8)$ & $17,565(16.7)$ & \\
\hline E5 and older years & & & & & \\
\hline No school cert & $30(0.3)$ & $10,618(99.7)$ & $10,648(10.3)$ & 0.7326 \\
\hline School cert & $67(0.3)$ & $25,290(99.7)$ & $25,357(24.5)$ & \\
\hline Apprenticeship/diploma & $125(0.3)$ & $40,030(99.7)$ & $40,155(38.7)$ & \\
\hline University degree or higher & $78(0.3)$ & $27,484(99.7)$ & $27,562(26.6)$ & \\
\hline Area & & & & \\
\hline
\end{tabular}

Area of residence $^{\dagger}$

\begin{tabular}{|c|c|c|c|c|}
\hline Major cities & $182(0.3)$ & $55,420(99.7)$ & $55,602(53.8)$ & 0.0228 \\
\hline Inner regional & $87(0.2)$ & 35,924 (99.8) & $36,011(34.8)$ & \\
\hline More remote & $26(0.2)$ & $11,723(99.8)$ & $11,749(11.4)$ & \\
\hline \multicolumn{5}{|l|}{ Marital status } \\
\hline Married/de facto & $247(0.3)$ & $85,021(99.7)$ & $85,268(81.6)$ & 0.6621 \\
\hline Not married/de facto & $52(0.3)$ & 19,135 (99.7) & $19,187(18.4)$ & \\
\hline \multicolumn{5}{|l|}{ Country of birth } \\
\hline Australia & $235(0.3)$ & $77,220(99.7)$ & $77,455(74.1)$ & 0.1148 \\
\hline Other & $66(0.2)$ & 27,011 (99.8) & $27,077(25.9)$ & \\
\hline \multicolumn{5}{|c|}{ Language spoken at home } \\
\hline English & $272(0.3)$ & $94,680(99.7)$ & $94,952(90.1)$ & 0.9991 \\
\hline Other & $30(0.3)$ & $10,445(99.7)$ & 10,475 (9.9) & \\
\hline \multicolumn{5}{|l|}{ Current work status } \\
\hline Paid work & $148(0.3)$ & 55,225 (99.7) & $55,373(52.9)$ & 0.0054 \\
\hline Retired & $118(0.3)$ & $42,490(99.7)$ & $42,608(40.7)$ & \\
\hline Other ${ }^{\ddagger}$ & $33(0.5)$ & 6,737 (99.5) & $6,770(6.5)$ & \\
\hline \multicolumn{5}{|c|}{$\begin{array}{l}\text { *Chi-square test was applied for comparison of category variables. The sum of each variable may not be } \\
\text { the same because of the missing values } \\
\text { 'Based on the Accessibility/Remoteness Index of Australia } \\
{ }^{\ddagger} \text { Other includes doing unpaid work/studying/looking after family/unemployed/disabled/sick }\end{array}$} \\
\hline
\end{tabular}

The prevalence of hypogonadism is estimated at five per 1000 men, ${ }^{2}$ but this may be an underestimate due to underdiagnosis. ${ }^{2,7}$ Our estimated initiation rate of three per 1000 patients per two- year period suggests more men are being treated than would be expected to be diagnosed with hypogonadism during this time frame; however, our estimate may be an underestimate as we did not capture all testosterone-prescribing, such as private scripts and scripts for patients with diabetes. Our initiation rate is higher than was seen in a study in the UK, where the yearly initiation rate was 0.5 per 1000 men in 2011, but lower than that in the US, where the yearly initiation rate was 7.6 per 1000 men in 2011. ${ }^{8}$ TRT prevalence rates from Canada ( 11 per 1000 men in 2012) ${ }^{10}$ and Sweden (six per 1000 men in 2014) ${ }^{17}$ were also higher than expected. The decrease in observed continuation rates may indicate that men are stopping therapy because the treatment does not relieve their symptoms. ${ }^{18}$

The factors associated with TRT initiation were similar to those seen in other studies. Studies in the US and Canada also observed that urban men were more likely to initiate TRT. ${ }^{10,19} \mathrm{We}$ observed higher initiation rates among men aged 55-74 years, and a Swedish study reported highest testosterone use among men aged $65-69$ years. ${ }^{17}$ Our findings showed that TRT initiation was more likely among men with low bone density, osteoporosis, fractures, and anxiety or depression. Similarly to our findings, studies in Canada, US and UK reported men using TRT had multiple comorbidities, ${ }^{8,10}$ and a US study found TRT was more likely among patients with depression and anxiety disorder. ${ }^{20}$ Such treatment may be beneficial given the known link between hypogonadism and low bone density, loss of motivation, mood or concentration. ${ }^{2}$ A previous Australian study reported that low testosterone was associated with higher cholesterol levels, ${ }^{21}$ and in our study, participants with higher cholesterol levels were more likely to have TRT initiated. This is concerning given recent research suggesting that TRT increases the risk of a coronary plaque in men. ${ }^{4}$

The updated 2016 ESA position statement supports TRT prescribing in men with hypogonadism with a confirmed laboratory diagnosis. ${ }^{1}$ The role of TRT in other settings is still not evidence-based. Low testosterone without elevated $\mathrm{LH}$ and FSH is due to chronic diseases as opposed to primary hypogonadism. ${ }^{1}$ Adverse effects, particularly increased cardiovascular risk, are still a concern. ${ }^{4}$ 
A revised clinical practice guideline from Andrology Australia ${ }^{22}$ and a recent published review ${ }^{23}$ also suggest there is no evidence-based role for TRT in managing erection difficulty.

We found that $60 \%$ of participants had no record of a hormone test before TRT initiation, similar to other findings. ${ }^{8,10}$ The lack of testosterone measurement was contrary to the 2000 ESA guidelines. ${ }^{2}$ The revised PBS guidelines in 2015 require a higher diagnostic threshold as well as a consultation with a specialist; since their release, testosterone PBS prescription rates have fallen, with a striking decline after 2015 in new testosterone prescriptions among men aged $40-80$ years. ${ }^{24}$ However, GPs have suggested these restrictions may lead to more underdiagnosis because of long waiting periods for specialists and the cost of private prescriptions. ${ }^{25}$ Hypogonadism remains significantly undertreated in Australia, ${ }^{7}$ but concerns about testosterone overuse may be overshadowing the underdiagnosis and undertreatment of androgen deficiency.

\section{Strengths and limitations}

A strength of our study is the inclusion of all prescriptions and medical services captured by the PBS and MBS, and the participants' detailed characteristics from the 45 and Up Study. In database studies we are limited by the data available. The limitations in this study include the lack of data regarding non-PBS testosterone prescriptions, DVA-scheme prescriptions and visits to specialists where a claim is not made through the MBS. A diagnosis of testosterone deficiency is also not recorded in the PBS and MBS databases.

PBS prescriptions accounted for approximately $70 \%$ of all TRT prescriptions in $2010 .{ }^{7}$ One limitation of the current study is that our initiation rate is likely to be an underestimate. We excluded people with diabetes from the analysis as we were unable to differentiate between hormone tests for testosterone deficiency and insulin assays, but this group of men may also be subject to inappropriate prescription of testosterone given common non-specific symptoms and comorbidities. Removing this group would have an effect of underestimating the rate of initiation in the population. Another limitation is the potential overestimation of the percentage of patients having a testosterone test before TRT initiation, as the MBS item number for a testosterone test includes other tests (eg insulin and cortisol). Similarly, the percentage of men with a relevant specialist visit may be an overestimate. Additionally, clinical characteristics recorded in the 45 and Up Study are self-reported, and we can only analyse the relevant associated factors that were collected in the study database. Finally, the participation rate of about $18 \%$ of the 45 and Up Study cohort means that great care should be taken if generalising these statistics to the general population.

\section{Implications for general practice}

Our findings suggest that testosterone prescribing occurred outside of the 2000 ESA guidelines, which were current at the time. This may be attributed to a combination of factors including prescribing practices of individual clinicians and consumer requests for therapy. The lack of hormone assays performed in men receiving TRT suggests inadequate diagnostic and monitoring activities by the prescribing clinicians. The PBS restrictions were introduced in April 2015, which may have added barriers to men requiring TRT but might also be driving GPs to prescribe privately, putting more men at a disadvantage.

To ensure appropriate TRT prescribing, evidence-based education programs for health professionals that highlight existing guidelines and how to address inappropriate patient requests for testosterone, such as those provided by Andrology Australia (www. andrologyaustralia.org), are essential. Along with evidence-based consumer campaigns, these could discredit false testosterone advertising claims and ensure underdiagnosed and undertreated cases are given due attention.

\section{Authors}

Yan Cheng PhD, Senior Research Officer, Family Planning NSW, NSW. wendyc@fpnsw.org.au Deborah Bateson MA, MSc, MBBS, Medical Director, Family Planning NSW, NSW; Clinical Associate Professor, The University of Sydney, NSW
Kristine Concepcion MPH, MHS, MD, Research Officer, Family Planning NSW, NSW

Mary Stewart MBBS, MPH, Senior Medical Officer Research and Education, Family Planning NSW, NSW Michael Lowy MPsychMed, Men's health physician, The Male Clinic; Lecturer, Family Planning NSW, NSW; Lecturer, The University of Sydney, NSW

Sally Sweeney BSc (Med), MBBS, FRACGP, Medical Officer, Family Planning NSW, NSW

Jane Estoesta MMedStat, Director Research Centre, Family Planning NSW, NSW

Kevin McGeechan PhD, Consultant Statistician, Family Planning NSW, NSW; Senior Lecturer, The University of Sydney School of Public Health, NSW Competing interests: None.

Provenance and peer review: Not commissioned, externally peer reviewed.

\section{Acknowledgements}

This research was completed using data collected through the 45 and Up Study (www.saxinstitute. org.au). The 45 and Up Study is managed by the Sax Institute in collaboration with major partner Cancer Council NSW; and partners: the National Heart Foundation of Australia (NSW Division); NSW Ministry of Health; NSW Government Family \& Community Services - Ageing, Carers and the Disability Council NSW; and the Australian Red Cross Blood Service. We thank the many thousands of people participating in the 45 and Up Study.

\section{References}

1. Yeap BB, Grossmann M, McLachlan Rl, et al. Endocrine Society of Australia position statement on male hypogonadism (part 1): Assessment and indications for testosterone therapy. Med J Aust 2016;205(4):173-78.

2. Conway AJ, Handelsman DJ, Lording DW, Stuckey B, Zajac JD. Use, misuse and abuse of androgens. The Endocrine Society of Australia consensus guidelines for androgen prescribing. Med J Aust 2000;172(5):220-24.

3. Huo S, Scialli AR, McGarvey S, et al. Treatment of men for "low testosterone": A systematic review. PLoS One 2016;11(9):e0162480. doi: 10.1371/ journal.pone.0162480.

4. Budoff MJ, Ellenberg SS, Lewis CE, et al. Testosterone treatment and coronary artery plaque volume in older men with low testosterone. JAMA 2017;317(7):708-16. doi: 10.1001/jama.2016.21043.

5. Roy CN, Snyder PJ, Stephens-Shields AJ, et al. Association of testosterone levels with anemia in older men: A controlled clinical trial. JAMA Intern Med 2017;177(4):480-90. doi: 10.1001/ jamainternmed.2016.9540.

6. Snyder PJ, Bhasin S, Cunningham GR, et al. Effects of testosterone treatment in older men. N Engl J Med 2016;374(7):611-24. doi: 10.1056/ NEJMoa1506119.

7. Handelsman DJ. Pharmacoepidemiology of testosterone prescribing in Australia, 1992-2010. Med J Aust 2012;196(10):642-45.

8. Layton JB, Li D, Meier CR, et al. Testosterone lab testing and initiation in the United Kingdom and the United States, 2000 to 2011. J Clin Endocrinol Metab 2014;99(3):835-42. doi: 10.1210/jc.2013-3570.

9. Handelsman DJ. Global trends in testosterone prescribing, 2000-2011: Expanding the spectrum of prescription drug misuse. Med J Aust 2013;199(8):548-51.

10. Piszczek J, Mamdani M, Antoniou T, Juurlink DN, Gomes T. The impact of drug reimbursement policy on rates of testosterone replacement therapy among older men. PLoS One 2014;9(7):e98003. doi: 10.1371/journal.pone.0098003. 
Table 2. Clinical characteristics of participants who had testosterone replacement therapy (TRT) initiation or not in the two-year follow-up (n/\%)

Clinical characteristics

TRT initiation

( $n=302$ )

Body mass index

Underweight $\left(<18.5 \mathrm{~kg} / \mathrm{m}^{2}\right)$

Normal weight $\left(18.5\right.$ to $\left.<25 \mathrm{~kg} / \mathrm{m}^{2}\right)$

Overweight $\left(25\right.$ to $\left.<30 \mathrm{~kg} / \mathrm{m}^{2}\right)$

Obese $\left(\geq 30 \mathrm{~kg} / \mathrm{m}^{2}\right)$

Smoking status

Never smoker

Past smoker

Current smoker

Alcohol consumption'

None

$\leq 14$ drinks/week

$>14$ drinks/week

Physical activity level

At risk (<150 min per week)

Not at risk ( $\geq 150$ min per week)

Physical impairment

\begin{tabular}{|c|c|c|c|c|}
\hline No limitation(score of 100) & $60(0.2)$ & 33,223 (99.8) & $33,283(37.5)$ & $<0.0001$ \\
\hline Minor limitation (90-99) & $73(0.3)$ & $29,623(99.7)$ & $29,696(33.5)$ & \\
\hline Moderate limitation (60-89) & $72(0.4)$ & $18,204(99.6)$ & $18,276(20.6)$ & \\
\hline Severe limitation(0-59) & $44(0.6)$ & 7,473 (99.4) & $7,517(8.5)$ & \\
\hline \multicolumn{5}{|l|}{ Fruit and vegetable intake } \\
\hline $\begin{array}{l}\text { Adequate ( } \geq 2 \text { servings of fruit and } \geq 5 \text { servings of vegetables } \\
\text { per day) }\end{array}$ & $36(0.2)$ & $14,688(99.8)$ & $14,724(17.4)$ & 0.2247 \\
\hline $\begin{array}{l}\text { Inadequate ( }<2 \text { servings of fruit or }<5 \text { servings of vegetables } \\
\text { per day) }\end{array}$ & $212(0.3)$ & $69,505(99.7)$ & $69,717(82.6)$ & \\
\hline \multicolumn{5}{|l|}{ Self-rated health } \\
\hline Excellent & $21(0.1)$ & $15,029(99.9)$ & $15,050(14.7)$ & $<0.0001$ \\
\hline Very good & $94(0.2)$ & 38,963 (99.8) & $39,057(38.2)$ & \\
\hline Good & $103(0.3)$ & $35,241(99.7)$ & $35,344(34.6)$ & \\
\hline Fair & $50(0.5)$ & $11,012(99.5)$ & $11,062(10.8)$ & \\
\hline Poor & $21(1.2)$ & $1,767(98.8)$ & $1,788(1.8)$ & \\
\hline \multicolumn{5}{|l|}{ Long-term illness or disability } \\
\hline Yes & $30(0.7)$ & 4,030 (99.3) & $4,060(4.0)$ & $<0.0001$ \\
\hline No & $255(0.3)$ & $96,430(99.7)$ & $96,685(96.0)$ & \\
\hline \multicolumn{5}{|l|}{ History of enlarged prostate } \\
\hline Yes & $49(0.3)$ & $16,857(99.7)$ & $16,906(16.0)$ & 0.9283 \\
\hline No & $253(0.3)$ & $88,270(99.7)$ & $88,523(84.0)$ & \\
\hline \multicolumn{5}{|l|}{ History of prostate removal operation } \\
\hline Yes & $25(0.3)$ & $8,575(99.7)$ & $8,600(8.2)$ & 0.9387 \\
\hline No & $277(0.3)$ & $96,552(99.7)$ & $96,829(91.8)$ & \\
\hline
\end{tabular}

TRT non-initiation

( $n=105,127)$

$21(0.3)$

$58(0.2)$

$129(0.3)$

$94(0.5)$

$142(0.3)$

$138(0.3)$

$20(0.2)$

$81(0.4)$

$146(0.3)$

$71(0.3)$

$102(0.4)$

$125(0.3)$

$25,990(99.6)$

$49,565(99.7)$

$26,092(34.4)$

0.0009

$49,690(65.6)$

\begin{tabular}{c}
$6,456(6.1)$ \\
\hline $31,494(29.9)$ \\
\hline $47,389(45)$ \\
\hline $20,090(19.1)$
\end{tabular}

$52,752(50.3)$

0.3155

$43,862(41.8)$

$8,220(7.8)$

$22,911(22)$
$55,313(53.2)$

$25,817(24.8)$

$(55,167(99.7)$

\subsection{9}

$25,746(99.7)$

(26,


Table 2. Clinical characteristics of participants who had testosterone replacement therapy (TRT) initiation or not in the two-year follow-up (n/\%) (cont'd)

\begin{tabular}{|c|c|c|c|c|}
\hline Clinical characteristics & $\begin{array}{l}\text { TRT initiation } \\
\quad(\mathrm{n}=302)\end{array}$ & $\begin{array}{l}\text { TRT non-initiation } \\
\quad(\mathrm{n}=105,127)\end{array}$ & $\begin{array}{c}\text { Total } \\
(\mathrm{n}=105,429)\end{array}$ & $P^{*}$ \\
\hline \multicolumn{5}{|l|}{ History of prostate cancer } \\
\hline Yes & $12(0.2)$ & $6,173(99.8)$ & $6,185(5.9)$ & 0.1609 \\
\hline No & $290(0.3)$ & $98,954(99.7)$ & $99,244(94.1)$ & \\
\hline \multicolumn{5}{|l|}{ Prostate symptom score } \\
\hline $\mathrm{P}_{50}-\mathrm{P}_{75}$ & $44(0.4)$ & 11,726 (99.6) & $11,770(18.1)$ & \\
\hline Above $\mathrm{P}_{75}$ & $65(0.4)$ & $15,824(99.6)$ & $15,889(24.4)$ & \\
\hline \multicolumn{5}{|l|}{ Erection difficulty } \\
\hline Yes & $209(0.3)$ & $77,494(99.7)$ & $77,703(83.6)$ & 0.0194 \\
\hline No & $213(0.3)$ & $78,428(99.7)$ & $78,641(74.6)$ & \\
\hline \multicolumn{5}{|c|}{ Treatment for osteoporosis or low bone density last month } \\
\hline Yes & $24(1.2)$ & $2,066(98.8)$ & $2,090(2.0)$ & $<0.0001$ \\
\hline No & $278(0.3)$ & 103,061 (99.7) & $103,339(98.0)$ & \\
\hline \multicolumn{5}{|l|}{ Bone broken in last 5 years } \\
\hline Yes & $48(0.5)$ & 8,709 (99.5) & $8,757(8.3)$ & $<0.0001$ \\
\hline No & $254(0.3)$ & $96,418(99.7)$ & $96,672(91.7)$ & \\
\hline \multicolumn{5}{|c|}{ Psychological distress (K10 scale) } \\
\hline No & $242(0.3)$ & $89,452(99.7)$ & $89,694(85.1)$ & \\
\hline \multicolumn{5}{|l|}{ History of high blood pressure } \\
\hline Yes & $126(0.3)$ & 37,417 (99.7) & 37,543 (35.6) & 0.0263 \\
\hline No & $176(0.3)$ & $67,710(99.7)$ & 67,886 (64.4) & \\
\hline \multicolumn{5}{|c|}{ History of high blood cholesterol } \\
\hline Yes & $75(0.5)$ & $15,192(99.5)$ & 15,267 (14.5) & $<0.0001$ \\
\hline No & $227(0.3)$ & $89,935(99.8)$ & $90,162(85.5)$ & \\
\hline \multicolumn{5}{|l|}{ History of stroke } \\
\hline Yes & $14(0.4)$ & 3,148 (99.6) & $3,162(3.0)$ & 0.0949 \\
\hline No & $288(0.3)$ & $101,979(99.7)$ & $102,267(97.0)$ & \\
\hline \multicolumn{5}{|l|}{ History of anxiety/depression } \\
\hline Yes & $80(0.6)$ & 12,717 (99.4) & $12,797(14.1)$ & $<0.0001$ \\
\hline No & $193(0.3)$ & 77,890 (99.8) & $78,083(85.9)$ & \\
\hline
\end{tabular}

${ }^{*}$ Chi-square test was applied for comparison of category variables. The sum of each variable may not be the same because of the missing values

'The categorisation of alcohol consumption is based on NHMRC. Australian guidelines to reduce health risks from drinking alcohol. Canberra: Australian Government National Health and Medical Research Council 2009 
Table 3. Factors associated with testosterone replacement therapy initiation in the two-year follow-up $(n=105,429)$

\begin{tabular}{lcccc}
\hline Factors & Group & AOR & $95 \% \mathrm{Cl}$ & $P$ \\
\hline Age & $\begin{array}{c}\text { 45-54 years (reference } \\
\text { group) }\end{array}$ & & & 0.0008 \\
\hline & $55-64$ years & 1.82 & $1.31,2.51$ & \\
\hline Area of residence & $65-74$ years & 1.72 & $1.11,2.67$ & \\
\hline & 75 and older years & 1.19 & $0.68,2.07$ & \\
\hline & Major cities (ref) & & & 0.0044 \\
\hline & Inner reginal & 0.68 & $0.52,0.89$ & \\
\hline & More remote & 0.61 & $0.40,0.93$ & \\
\hline
\end{tabular}

Treatment for osteoporosis

or low bone density last

month

No (ref) $\quad<0.0001$

\begin{tabular}{|c|c|c|c|c|}
\hline & Yes & 2.87 & $1.82,4.51$ & \\
\hline \multirow[t]{2}{*}{ Bone broken in last 5 years } & No (ref) & & & 0.0008 \\
\hline & Yes & 1.73 & $1.26,2.39$ & \\
\hline \multirow[t]{2}{*}{$\begin{array}{l}\text { History of high blood } \\
\text { cholesterol }\end{array}$} & No (ref) & & & 0.0015 \\
\hline & Yes & 1.57 & $1.19,2.08$ & \\
\hline \multirow[t]{2}{*}{$\begin{array}{l}\text { History of anxiety/ } \\
\text { depression }\end{array}$} & No (ref) & & & $<0.0001$ \\
\hline & Yes & 2.04 & $1.52,2.75$ & \\
\hline \multirow[t]{5}{*}{ Self-rated health } & Excellent (ref) & & & 0.0467 \\
\hline & Very good & 1.44 & $0.89,2.33$ & \\
\hline & Good & 1.43 & $0.86,2.39$ & \\
\hline & Fair & 1.65 & $0.90,3.04$ & \\
\hline & Poor & 3.26 & $1.50,7.12$ & \\
\hline
\end{tabular}

Also adjusted by other demographics and clinical characteristics present in table 1 and 2. Covariates with $P$ value $>0.05$ were not shown in the table

$A O R$, adjusted odds ratio; $\mathrm{Cl}$, confidence intervals.

11. Department of Health (DoH). Schedule of Pharmaceutical Benefits. Effective 1 March 2015-31 March 2015. Canberra: DoH, 2015. Available at www.pbs.gov.au/publication/ schedule/2015/03/2015-03-01-general-schedule. pdf [Accessed 18 June 2018].

12. 45 and Up Study Collaborators, Banks $\mathrm{E}$, Redman S, et al. Cohort profile: The 45 and up study. Int J Epidemiol 2008;37(5):941-47.

13. World Health Organization (WHO). Global recommendations on physical activity for health. Geneva: WHO, 2010.

14. Johar M, Savage E. Discovering unhealthiness: Evidence from cluster analysis. Ann Epidemiol 2013;23(10):614-19. doi: 10.1016/j. annepidem.2013.07.015.

15. Australian Bureau of Statistics (ABS). 4817.0.55.001 - Information paper: Use of the Kessler Psychological Distress Scale in ABS health surveys, Australia, 2007-08. Canberra:
ABS, 2012. Available at www.abs.gov.au/ausstats/ abs@.nsf/Lookup/4817.0.55.001Chapter92007-08 [Accessed 18 June 2018].

16. Yuan YC. Multiple imputation for missing data: Concepts and new development (Version 9.0). Rockville, MD: AS Institute Inc, 2010;49:1-11.

17. Bjerkeli PJ, Mulinari S, Merlo J. Testosterone prescribing in the population-A short social epidemiological analysis in Sweden. Pharmacoepidemiol Drug Saf 2016;25(1):11-15. doi: 10.1002/pds.3836.

18. Schoenfeld MJ, Shortridge E, Cui Z, Muram D. Medication adherence and treatment patterns for hypogonadal patients treated with topical testosterone therapy: A retrospective medical claims analysis. J Sex Med 2013;10(5):1401-09. doi: 10.1111/jsm.12114.

19. Rosen RC, Seftel AD, Ruff DD, Muram D. A pilot study using a web survey to identify characteristics that influence hypogonadal men to initiate testosterone replacement therapy. Am J Mens Health 2018;12(3):567-74. doi: 10.1177/1557988315625773.

20. Jasuja GK, Bhasin S, Reisman Jl, et al. Who gets testosterone? Patient characteristics associated with testosterone prescribing in the veteran affairs system: A cross-sectional study. J Gen Intern Med 2017;32(3):304-11. doi: 10.1007/s11606-016-3940-7.

21. Atlantis E, Martin SA, Haren MT, et al. Demographic, physical and lifestyle factors associated with androgen status: The Florey Adelaide Male Ageing Study (FAMAS). Clin Endocrinol (Oxf) 2009;71(2):261-72. doi: 10.1111/j.1365-2265.2008.03463.x.

22. Andrology Australia. Androgen deficiency: Diagnosis and management. Melbourne: Andrology Australia, 2018. Available at https://andrologyaustralia.org/ wp-content/uploads/clinical-summary-guide-04. pdf [Accessed 19 June 2018].

23. Rastrelli G, Corona G, Maggi M. Testosterone and sexual function in men. Maturitas 2018;112:46-52. doi: 10.1016/j.maturitas.2018.04.004.

24. Handelsman DJ. Pharmacoepidemiology of testosterone: Curbing off-label prescribing. Pharmacoepidemiol Drug Saf 2017;26(10):1248-55 doi: 10.1002/pds.4284.

25. Klein A. Curbs on GP testosterone scripts 'haphazard'. Australian Doctor. 5 June 2015 Available at www.australiandoctor.com.au/ news/curbs-gp-testosterone-scripts-haphazard [Accessed 19 June 2018]. 


\section{Appendix}

\section{Measures}

\section{Outcomes}

The initiation of testosterone replacement therapy (TRT) was defined as a man being dispensed with a testosterone-based drug (testosterone, testosterone enanthate and testosterone undecanoate) during the 24 months following the completion of baseline survey among males who did not receive TRT in the 24 months prior to the baseline survey (2006-2009). Dispensed testosterone medications were identified from the Pharmaceutical Benefits Scheme (PBS) dataset as those with Anatomical Therapeutic Chemical (ATC) classification codes beginning with G03BA03.

Participants who self-reported holding a Department of Veterans' Affairs card were excluded, as they have access to a broader range of subsided medications under a separate government program.

We identified whether men had a hormone test or visited a specialist in the six months before the initiation of TRT. A hormone test is derived from MBS item number 66695, which is defined as 'Quantitation in blood or urine of hormones and hormone binding proteins - ACTH, aldosterone, androstenedione, C-peptide, calcitonin, cortisol, DHEAS, 11-deoxycortisol, dihydrotestosterone, FSH, gastrin, glucagon, growth hormone, hydroxyprogesterone, insulin, $\mathrm{LH}$, oestradiol, oestrone, progesterone, prolactin, $\mathrm{PTH}$, renin, sex hormone binding globulin, somatomedin C(IGF-1), free or total testosterone, urine steroid fraction or fractions, vasoactive intestinal peptide, -1 test'. ${ }^{1}$ Although the Medicare Benefits Schedule (MBS) item 66695 covers most of the hormone tests applying to the diagnosis of testosterone deficiency, it is also used when insulin tests are ordered, hence we excluded participants with a self-reported history of diabetes, recent treatment for diabetes (in last month) or a prescription filled for a diabetes drug (ATC classification codes beginning with A10) from 2004 to 2014. The definition of a specialist visit is based on a combination of MBS groups under MBS Category 1 attendances, ${ }^{2}$ which include other non-referred attendances, specialist attendances, consultant physician attendances and prolonged attendances. The specialist visit is not able to differentiate an endocrinologist, urologist or Member of the Australian Chapter of Sexual Health Medicine who are relevant to the diagnosis and treatment of TRT.

\section{Explanatory variables}

We examined whether the following demographic and clinical characteristics were associated with the initiation of TRT. The demographics characteristics were: age; education (no school certificate, school certificate, apprenticeship/trade/ certificate/diploma or university degree or higher); area of residence based on the Accessibility/Remoteness Index of Australia (major cities, inner regional or more remote); marital status (married/ de facto or not married/de facto); country of birth (Australia or other); language spoken at home (English or other); current work status (paid work, retired or other [doing unpaid work/studying/looking after family/unemployed/disabled/ sick]); body mass index (BMI, categorised as underweight $\left[<18.5 \mathrm{~kg} / \mathrm{m}^{2}\right]$, normal weight $\left[18.5\right.$ to $\left.<25 \mathrm{~kg} / \mathrm{m}^{2}\right]$, overweight $\left[25\right.$ to $\left.<30 \mathrm{~kg} / \mathrm{m}^{2}\right]$ and obese $\left[\geq 30 \mathrm{~kg} / \mathrm{m}^{2}\right]$ according to World Health Organization [WHO] criteria).

The clinical characteristics included: smoking status (never, past, current); alcohol consumption (drinks per week categorised as none, $\leq 14$ drinks/week, >14 drinks/week ${ }^{3}$ ); physical activity (based on the total time one spent on moderate-tovigorous-intensity physical activity and categorised as at-risk or not according to WHO recommendations on physical activity for health $\left.{ }^{4}\right) ;$ physical impairment (derived from the physical functioning scale of the SF-36 health survey ${ }^{5}$ and categorised as no limitation (score of 100), minor limitations (90-99), moderate limitations (60-89), severe limitations (0-59); fruit and vegetable (including both raw and cooked vegetables) intake was assessed as servings per day and categorised as adequate ( $\geq 2$ servings of fruit and $\geq 5$ servings of vegetables per day) or inadequate (less than these amounts) according to the National Health and Medical Research Council guidelines; 7,8 self-rated health (categorised as excellent, very good, good, fair or poor); need help due to long-term illness or disability (yes/ no); history of enlarged prostate/prostate cancer/prostate removal operation (based on self-reported ever doctor-diagnosed enlarged prostate and prostate cancer, and prostate removal operation and categorised as yes/no, respectively); prostate symptom score (quartiles based on the international prostate symptom ${ }^{9}$ ); vasectomy operation (yes/no); bone broken in last five years (yes/no). Psychological distress (based on responses to the Kessler 10 scale $^{10}$ and categorised as low [score of $<16$ ], moderate [16-21], high [22-29] and very high [30-50]) according to the classification of Australian Bureau of Statistics surveys. ${ }^{11}$ In addition, we created dichotomous variables for history of heart disease, high blood pressure, high blood cholesterol, stroke and anxiety/depression based on self-reported (at baseline) doctor-diagnosis of, or recent treatment in the last month for, these conditions. We also created a dichotomous variable for treatment for osteoporosis or low bone density based on self-reported (at baseline) treatment in the last month for this condition. We created an additional dichotomous variable for erection difficulty based on self-reported inability to maintain an erection for satisfactory sexual activity.

\section{Supplementary references}

1. Department of Health (DoH). Medicare Benefits Schedule - Item 66695. Canberra: DoH, 2017.

2. Department of Health $(\mathrm{DoH})$. Medicare Benefits Schedule Book - Category 1. Canberra: DoH, 2017.

3. National Health and Medical Research Council (NHMRC). Australian guidelines to reduce health risks from drinking alcohol. Canberra: NHMRC 2009

4. World Health Organization (WHO). Global recommendations on physical activity for health. Geneva: WHO, 2010.

5. Stewart AL. Measuring functioning and well-being The medical outcomes study approach. Durham, US: Duke University Press, 1992.

6. Johar M, Savage E. Discovering unhealthiness: Evidence from cluster analysis. Ann Epidemiol 2013;23(10):614-19. doi: 10.1016/j. annepidem.2013.07.015.

7. Gubhaju L, Banks E, MacNiven R, et al. Physical functional limitations among Aboriginal and non-Aboriginal older adults: Associations with socio-demographic factors and health. PLoS One 2015;10(9):e0139364. doi: 10.1371/journal. pone.0139364.

8. National Health and Medical Research Coucil (NHMRC). Dietary guidelines for Australian adults. Canberra: NHMRC, 2003 
9. Bosch J, Hop W, Kirkels W, Schröder F. The International Prostate Symptom Score in a community-based sample of men between 55 and 74 years of age: Prevalence and correlation of symptoms with age, prostate volume, flow rate and residual urine volume. BJU Int 1995;75(5):622-30.

10. Kessler RC, Andrews G, Colpe LJ, et al. Short screening scales to monitor population prevalences and trends in non-specific psychological distress. Psychol Med 2002;32(6):959-76.

11. Australian Bureau of Statistics (ABS). 4817.0.55.001 - Information paper: Use of the Kessler Psychological Distress Scale in ABS health surveys, Australia, 2007-08. Canberra: ABS, 2012. Available at www.abs.gov.au/ausstats/ abs@.nsf/Lookup/4817.0.55.001Chapter92007-08 [Accessed 19 June 2018]. 